九州大学学術情報リポジトリ

Kyushu University Institutional Repository

\title{
Stochastic and Three Dimensional Computation Model for Analyzing Soil Water Balance on Comp lex Topography
}

Lamsal, Khadananda

Laboratory of Irrigation and Water Utilization Engineering, Faculty of Agriculture, Kyushu University

Kuroda, Masaharu

Laboratory of Irrigation and Water Utilization Engineering, Faculty of Agriculture, Kyushu University

Nakano, Yoshisuke

Laboratory of Irrigation and Water Utilization Engineering, Faculty of Agriculture, Kyushu University

https://doi.org/10.5109/24082

出版情報：九州大学大学院農学研究院紀要. 39 (3/4)，pp.197-220，1995-03. Kyushu University バージョン：

権利関係 : 


\title{
Stochastic and Three Dimensional Computation Model for Analyzing Soil Water Balance on Complex Topography
}

\author{
K hadananda Lamsal, M asaharu Kuroda and Yoshisuke Nakano
}

\author{
Laboratory of Irrigation and Water Utilization Engineering, \\ Faculty of Agriculture, Kyushu University, Fukuoka 812-81, Japan \\ (Received November 24, 1994)
}

\begin{abstract}
The evapotranspiration is governed by solar radiation. The acception of solar radiation by land is affected by astronomical, climatological and topographical conditions. Moreover, the amount of accepted solar radiation by land differs with steepness and facing direction, although, astronomical and climatological parameters remaining the same. Thus, a study in evapotranspiration on complex topography is necessary to investigate the efficient guidelines for proper irrigation scheduling to meet crop water requirement and for saving water. The results showed that evapotranspiration differs with steepness and facing direction of field in winter, whereas, evapotranspiration is not remarkably different in summer. This research is also oriented to reflect the impact of drought occurring season in annual amount of water application. The distributed annual amount of water applications are significantly different from one year to another in all topographic conditions, although, the annual rainfalls are almost similar in all years. Furthermore, the amount of annual water applications are differed with facing direction of field. Therefore, the irrigation designers or planners are awared by this research to consider the topographic conditions while designing the capacities of irrigation systems.
\end{abstract}

\section{INTRODUCTION}

\section{General background}

The water is one of the limiting factors for intensive crop cultivation as well as for obtaining the higher yield, even though, the crops have potentialities of higher production. J. W. Jones et. al. (1972) mentioned that the problems of making decisions concerning crop production are complicated by the uncertainty of the weather. Therefore, stochastic approaches are practiced for climatological parameters estimation. The solar radiation is one of the important factors for soil water consumption. The daily amount of total accepted solar radiation is estimated by the daily amount of global solar radiation with considering the topographic conditions. Because the vertical component of incoming solar radiation on flat areas and hill slopes facing in various directions are different. The shading effect of high hills to lower sides of the hills are also common to intercept the direct solar radiation. On the other hand, the amount of diffused solar radiation is also reduced due to presence of high hills, sea and inclined topography. These conditions intercept the hemisphere and make the view factor smaller than the unity view factor. The daily amount of evapotranspiration is solely depended on the daily accepted solar radiation.

The soil water balance is affected by the distribution pattern of rainfall and global solar radiation. The distribution pattern of global solar radiation is depended on the daily amount of incoming and out going solar radiation. Moreover, the distribution 
pattern of global solar radiation are different in dry and rainy days for each months. The probabilities of dry and rainy days are able to be presented as the Markov Chain phenomenon. Due to this reason, the conditional probabilities for dry and rainy days should be considered according to Markov process. The daily rainfall and global solar radiation should be generated stochastically for dry and rainy days of each months.

\section{Purpose of research}

This research is designed to investigate the differences in the daily amount of the evapotranspiration and there by annual amount of the water application not only in flat areas but also in hill slopes facing in different directions with various degrees of slope to meet the crop water requirement. This research will, therefore, provide good guidelines for water saving procedures and for efficient irrigation scheduling on complex topography. It will minimize the water demand and ultimately leads to optimize the irrigation systems, for instance, the capacity of canals, the volume of water harvesting ponds, the size of pipelines etc, on the complex topography, which is the real world's issue for agricultural development.

\section{ANALOGIC EXPERIMENTATION}

\section{Location}

The purpose of this research is to investigate the water consumption analysis on complex topography. The analogic experiment was carried out by simulation analysis.

The Kikai Island is chosen as a research site. The Kikai Island comprises of hills, undulations and flat land areas with subtropical oceanic climate. The latitude of the experimental area is $28.23^{\circ} \mathrm{N}$. The altitude of the experimental area ranges from 0 to $200 \mathrm{~m}$. Figure 1 shows the location map of Kikai Island.

\section{Research procedure}

The parameters for climatological simulation process were derived by analyzing at least past 30 years'(1963-1992) climatological data such as daily rainfall, daily global solar radiation and so on. The climatological data of Kikai Island was not available for the sufficient numbers of past years. Therefore, the past actual climatological data of Naze, Amami Island was used for analysis because this Island is very close to Kikai Island. The three dimensional analysis has been applied to clarify the effect of various topographic conditions on water consumption. In the analysis the $\mathrm{X}$ axis has presented north to south direction, the $\mathrm{Y}$ axis has represented west to east direction and the $Z$ axis has presented altitude. A part of area $(3.5 \mathrm{~km} \times 3.5 \mathrm{~km})$ of Kikai Island was used for analogical experiments and the area was divided into grids of $100 \mathrm{~m}$ in both $\mathrm{X}$ and $\mathrm{Y}$ directions. The altitude $\mathrm{Z}$ on each meshed grid point was generated by the interpolation and extrapolation methods from inputted altitudes on each contour line. Figure 2 presents the obtained topographic map of experimental area. 


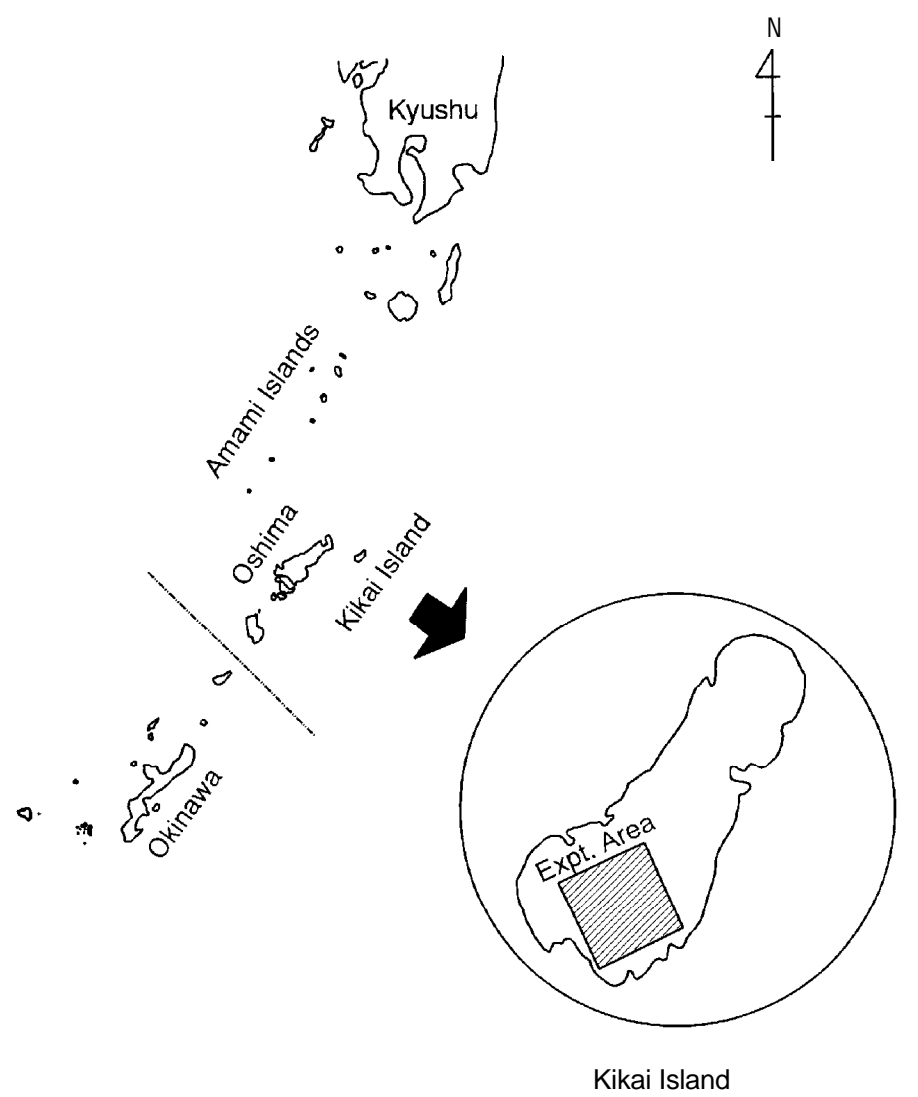

Fig. 1. Location of Kikai Island and experiment area.

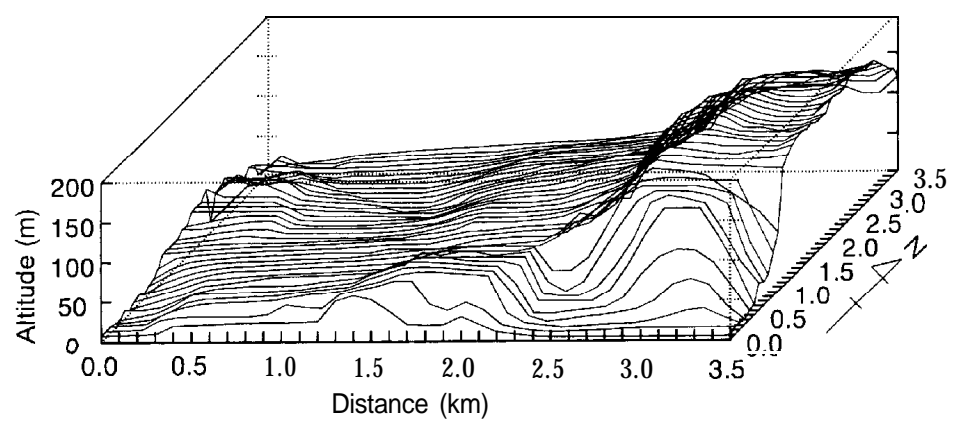

Fig. 2. Topographic feature of experiment area. 


\section{SOLAR RADIATION AND TOPOGRAPHY}

\section{Coordinate system for evaluating solar radiation}

The altitude, azimuth angle and directional cosines of the sun were the basis for the analysis. Figure 3 shows the coordinate system to evaluate the solar radiation. Moreover, the directional cosines of the sun were derived through the sun altitude and azimuth angle.

According to Tani(1974), the sun altitude $(\phi)$ and the azimuth angle (w) were given as,

$$
\begin{gathered}
\sin \phi=\cos \eta \cdot \cos \delta \cdot \cos \tau+\sin \eta \cdot \sin \delta \\
\sin \omega=\frac{\cos \delta \cdot \sin \tau}{\cos \phi}
\end{gathered}
$$

where,

$\eta=$ latitude of the experimental area.

$\delta=$ declination of the sun.

$\tau=$ solar time

The each components of the directional cosines of the sun are presented in Fig. 3 . The relations used to derive the directional cosines of the sun $\left(s_{1}, s_{2}, s_{3}\right)$ are as follows,

$$
\begin{gathered}
s_{1}=\cos \alpha=\cos \left(\frac{\pi}{2}-\phi\right) \cdot \sin \omega \\
s_{2}=\cos \beta=\sin \omega \cdot \cos \phi
\end{gathered}
$$

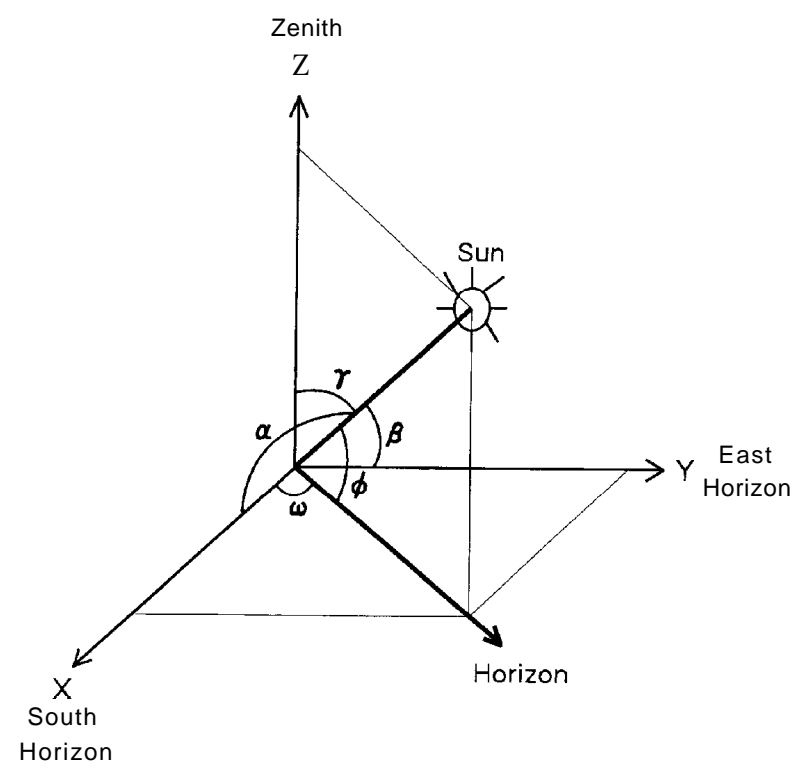

Fig. 3. Coordinate system for evaluating the solar radiation. 


$$
s_{3}=\cos \gamma=\cos \left(\frac{\pi}{2}-\phi\right)
$$

\section{Interception of direct solar radiation}

The interception of the direct solar radiation, by shading effect of high hills of one grid point to other grid points, was examined by the three dimensional geometric relations. Figure 4 shows the conceptual and mathematical configuration model for shading effect. The interception of direct solar radiation was examined by considering the two triangular plates. The. concept is AABC intercepts the direct solar radiation to $\mathrm{APQR}$ in Fig. 4. The directional cosines of line $\mathrm{AB}\left(l_{1}, l_{2}, l_{3}\right)$ and line $\mathrm{AC}$ $\left(m_{1}, m_{2}, m_{3}\right)$ were calculated to determine the directional cosines of AABC $\left(n_{1}, n_{2}, n_{3}\right)$. The directional cosines of line $\mathrm{AB}$ were derived as,

$$
\begin{aligned}
l_{1} & =\left(x_{2}-x_{1}\right) / d_{1} \\
l_{2} & =\left(y_{2}-y_{1}\right) / d_{1} \\
l_{3} & =\left(z_{2}-z_{1}\right) / d_{1}
\end{aligned}
$$

where,

$$
d_{1}=\left[\left(x_{2}-x_{1}\right)^{2}+\left(y_{2}-y_{1}\right)^{2}+\left(z_{2}-z_{1}\right)^{2}\right]^{\frac{1}{2}}
$$

In the same way, the directional cosines of line AC were determined as follows,

$$
\begin{aligned}
& m_{1}=\left(x_{3}-x_{1}\right) / d_{2} \\
& m_{2}=\left(y_{3}-y_{1}\right) / d_{2} \\
& m_{3}=\left(z_{3}-z_{1}\right) / d_{2}
\end{aligned}
$$

where,

$$
d_{2}=\left[\left(x_{3}-x_{1}\right)^{2}+\left(y_{3}-y_{1}\right)^{2}+\left(z_{3}-z_{3}\right)^{2}\right]^{\frac{1}{2}}
$$

Finally, the directional cosine of $\mathrm{ABC}$ were derived as,

$$
n_{1}=\left(l_{2} m_{3}-l_{3} m_{2}\right) / d_{3}
$$

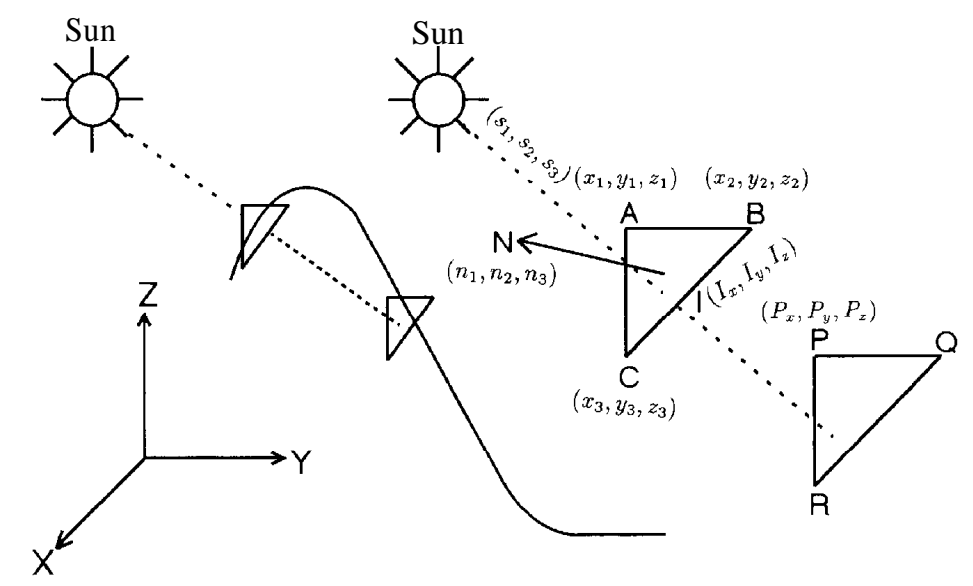

Fig. 4. Conceptual and mathematical model for the shading effect. 


$$
\begin{aligned}
& n_{2}=\left(l_{3} m_{1}-l_{1} m_{3}\right) / d_{3} \\
& n_{3}=\left(l_{1} m_{2}-l_{2} m_{1}\right) / d_{3}
\end{aligned}
$$

where,

$$
d_{3}=\left[\left(l_{2} m_{3}-l_{3} m_{2}\right)^{2}+\left(l_{3} m_{1}-l_{1} m_{3}\right)^{2}+\left(l_{1} m_{2}-l_{2} m_{1}\right)^{2}\right]^{\frac{1}{2}}
$$

According to Tajima et. al. (1977), the relations for examining interception of direct solar radiation due to presence of high hills on one grid point to other grid points are given as,

$$
\begin{aligned}
& I_{x}=P_{x}+s_{1} t \\
& I_{y}=P_{y}+s_{2} t \\
& I_{z}=P_{z}+s_{3} t
\end{aligned}
$$

where,

$\mathrm{t}=$ parameter given as

$$
t=-\frac{n_{1}\left(P_{x}-x_{1}\right)+n_{2}\left(P_{y}-y_{1}\right)+n_{3}\left(P_{z}-z_{1}\right)}{n_{1} s_{1}+n_{2} S_{2}+n_{3} S_{3}}
$$

$P_{x}, P_{y} \& P_{z}$ are the coordinates of an objected grid point, on which interception of direct solar radiation is to be examined, on $\mathrm{x}, \mathrm{y}$ and $\mathrm{z}$ direction, respectively.

$x_{1}, y_{1} \& z_{1}$ are the coordinates of an imaginary grid point, which is expected to intercept direct solar radiation on objected grid point, on $\mathrm{x}, \mathrm{y}$ and $\mathrm{z}$ direction, in order.

$n_{1}, n_{2} \& n_{3}$ directional cosine of an imaginary triangular plate with respect to $\mathrm{x}$, $\mathrm{y}$ and $\mathrm{z}$ directions.

$s_{1}, s_{2} \& s_{3}$ directional cosine of the sun with respect to $\mathrm{x}, \mathrm{y}$ and $\mathrm{z}$ directions.

$I_{x}, I_{y} \& I_{z}$ are the coordinates of the sun ray intersecting point on $\mathrm{x}, \mathrm{y}$ and $\mathrm{z}$ direction, respectively.

If $I_{x}, I_{y} \& I$, are within the range of $\mathrm{x}, \mathrm{y}$ and $\mathrm{z}$ coordinates of an imaginary triangular plate then interception of direct solar radiation occurs on the objected plate.

The theoretical approaches of above mentioned were applied to examine the interception of direct solar radiation on the actual topographic condition of the experimental area of Kikai Island. The obtained result of the interception of direct solar radiation, for example is presented in Fig. 5, by high hills of one grid point to

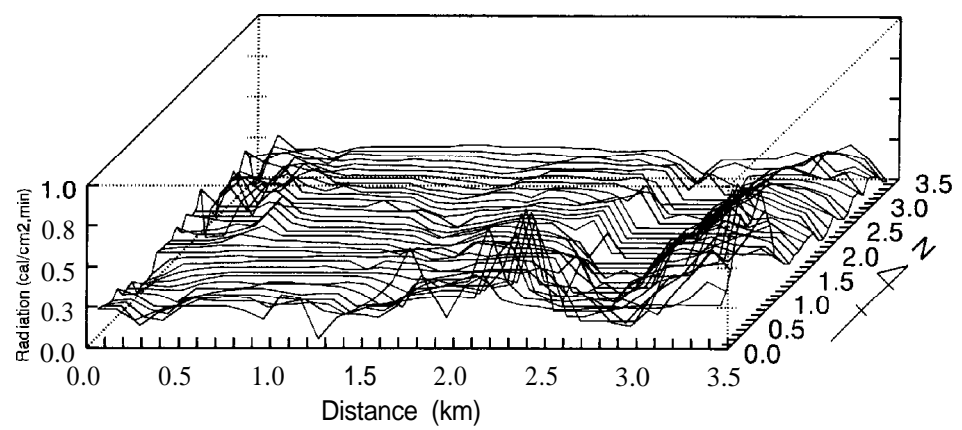

Fig. 5. Distribution of direct solar radiation on experimental area at 6 a.m. of June 15th. 
others on experimental area at 6 a.m. on $15^{\text {th }}$ June.

\section{Interception of diffused solar radiation}

The equation (49), in the following chapter, is used to compute the total accepted shortwave radiation on fields without any obstacles. The coefficient of the second and the third terms of the equation represent the view factor of hemisphere and horizon, respectively. The equation has a limitation for applying to the case of complex topography, because, the view factor can not be estimated by so simple relation in the presence of obstacles. Therefore, the view factor for those type of fields are determined by developing another geometric configurations as shown in Fig. 6.

The relations for view factor estimation on grid points lying on flat areas has given the form of,

$$
\begin{aligned}
& x=w_{1} R \\
& y=w_{2} R
\end{aligned}
$$

where,

$$
\begin{gathered}
w_{1}=\left(x_{i}-P_{x}\right) / d_{4} \\
w_{2}=\left(y_{i}-P_{x}\right) / d_{4} \\
d_{4}=\left[\left(x_{i}-P_{x}\right)^{2}+\left(y_{i}-P_{y}\right)^{2}+\left(z_{i}-P_{z}\right)^{2}\right]^{\frac{1}{2}}
\end{gathered}
$$

The values of $\mathrm{x}$ and $\mathrm{y}$ were plotted in a circle with an arbitrary constant radius $R$ (Fig. 6). Then, the area of shaded portion of the circle were determined to estimate the view factor for the grid points lying on the flat areas.

In addition, the degrees and factors of interception of hemisphere were further investigated on actual topographic condition of the experimental area by developing the other geometric configurations. The purpose of the procedure of above mentioned was to investigate the arrangement of various factors to intercept the hemisphere. It

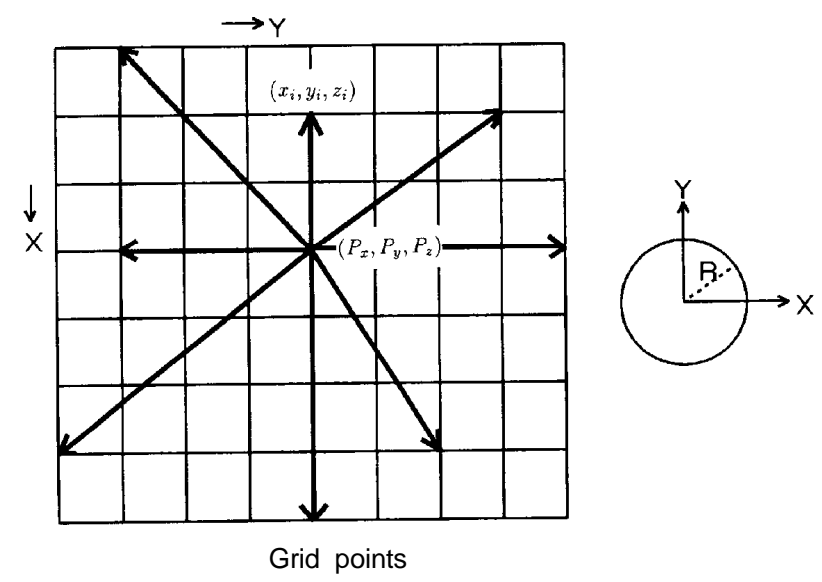

Fig. 6. Cornfiguration to estimate the view factor caused by hills. 
will provide a clear knowledge on how the hemisphere is intercepted by the various factors on complex topography, which is fundamental basis for diffused solar radiation estimation. The coordinate system of hill slope was developed for this analysis, which is presented in Fig. 7, and then coordinate transformation procedure was adopted. The geometric configuration for coordinate transformation is presented in Fig. 8.

The coordinates were transformed two dimensionally (i. e., x \& y) with considering the same origin. According to the relations mentioned by Tajima et. al. (1977) and

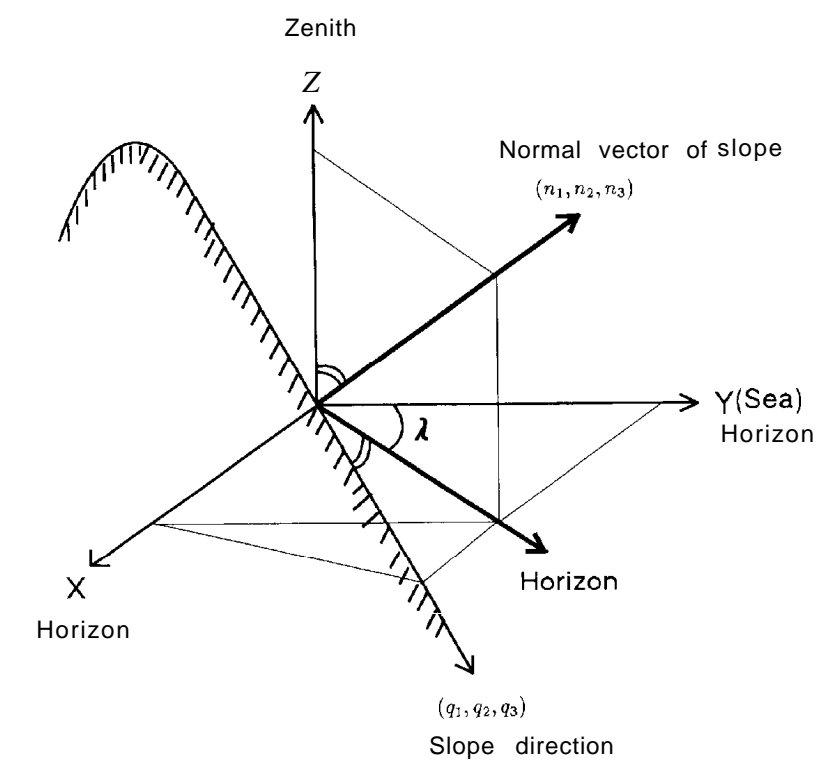

Fig. 7. Coordinate system of inclined field.

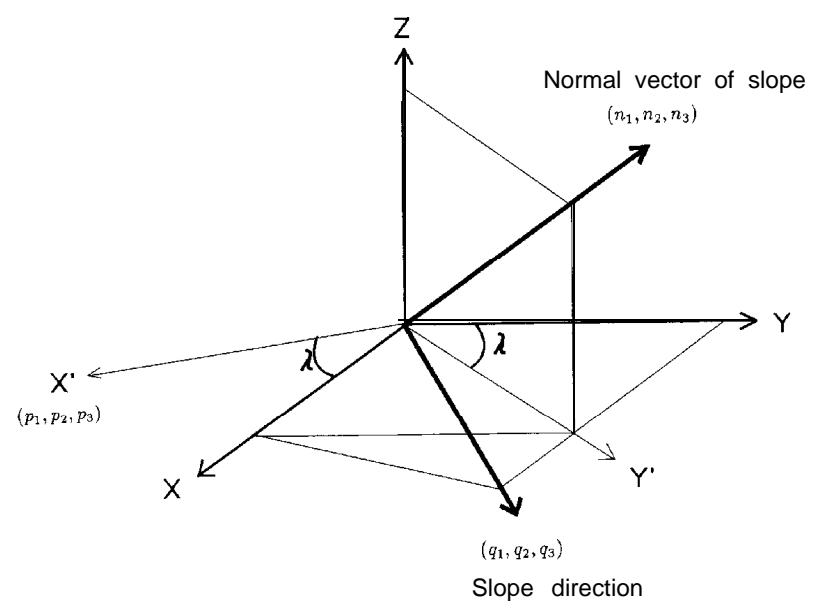

Fig. 8. Coordinate transformation for view factor estimation on inclined field. 
the relations given in Fig. 7 and Fig. 8 the coordinate transformation relations are reduced to,

$$
\begin{gathered}
\left(X^{\prime}\right)^{2}+\left(Y^{\prime}\right)^{2}=R^{2} \\
X=\cos \lambda X^{\prime}+\sin \lambda \mathrm{Y} \\
\mathbf{Y}=-\sin X^{\prime}+\cos \lambda \mathrm{Y} \\
X^{\prime \prime}=p_{1} \cdot X+p_{2} \cdot \mathrm{Y} \\
Y^{\prime \prime}=q_{1} \cdot X+q_{2} \cdot \mathrm{Y}
\end{gathered}
$$

where,

$$
\begin{aligned}
& q_{1}=\cos n_{1} \cdot \cos n_{3} / \sin n_{3} \\
& q_{2}=\cos n_{2} \cdot \cos n_{3} / \sin n_{3} \\
& q_{3}=\cos \left(n_{3}+\frac{\pi}{2}\right) \\
& p_{1}=\cos \lambda \\
& p_{2}=\cos \left(\lambda+\frac{\pi}{2}\right) \\
& p_{3}=\cos \left(\frac{\pi}{2}\right)=0 \\
& \lambda=\cos ^{-1}\left(\cos n_{2} / \sin n_{3}\right)
\end{aligned}
$$

The obtained values of $X^{\prime \prime}$ and $Y^{\prime}$ were plotted in the same circle of above mentioned with the same radius $R$ (Fig. 6).

The theoretical procedures of above mentioned were useful to investigate the arrangement of the various factors of hemisphere interception on the complex topography of experimental area of Kikai Island. The typical results are presented in Fig. 9. On the almost all grid points the hemisphere is intercepted in together by hills and sea because of inclined topography in small Island just like Kikai Island. But, on a few grid points the hemisphere is intercepted either by hills or, by sea and hills individually. There are a few cases of nominal hemisphere interception phenomenon.

\section{ASSESSMENT OF SOIL WATER BALANCE PARAMETERS}

\section{Markov process for predicting dry or rainy day}

The prediction of rainy or dry day is very important for soil water balance. The Markov theory was used to decide whether the day is rainy or dry at the time of predicting daily rainfall and daily global solar radiation. Because, the monthly distribution pattern of intensities of global solar radiations are different for rainy and dry days. Therefore, the previous time period was considered to calculate the monthly conditional probabilities of rainy and dry days according to Markov Chain phenomenon. A day was defined as dry, if less than $1.5 \mathrm{~mm}$ rainfall occurred on that day. The relations mentioned by M. Kuroda and Y. Nakano (1992) for conditional probabilities of dry and rainy days in a given month are presented as follows,

PDD is monthly conditional probability for dry day, which is defined as,

$$
\mathrm{PDD}=\Sigma \text { Dry days following a dry day } / \Sigma \text { Dry days }
$$




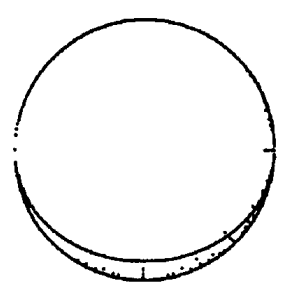

Interception of hemisphere together by sea and hills

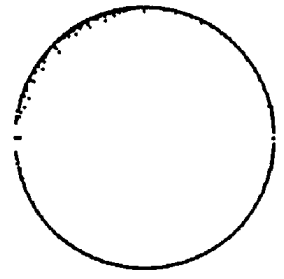

Interception of hemisphere only by hills

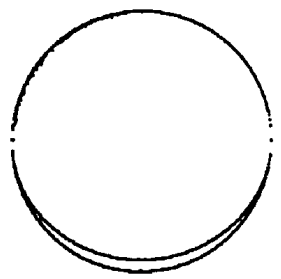

Interception of hemisphere by sea and hills individually

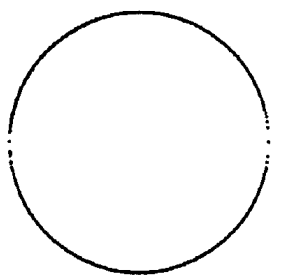

Almost no interception of hemisphere

Fig. 9. Typical examples showing the arrangement of factors of hemisphere interception. 
PWW is monthly conditional probability for rainy day, which is defined as,

$\mathrm{PWW}=\Sigma$ Rainy days following a rainy day $/ \Sigma$ Rainy days

\section{Prediction of daily global solar radiation}

The arbitrary method was adopted for stochastic global solar radiation generation for daily soil water balance analysis. The monthly probabilities of occurrence of particular intensities of daily global solar radiations were set separately for rainy and dry days with analyzing the data of the sufficient numbers of the past years. Then, cumulative probabilities were computed for particular intensities of daily global solar radiations, accordingly. The generation of global solar radiations were carried out in the simulation analysis for rainy and dry days with generating the random numbers. The procedures are presented as follows,

$$
\text { if } \sum_{i=1}^{s-1} P Q_{i}<\xi \leq \sum_{i=1}^{s} P Q_{i} \quad \text { then } Q=i,
$$

when $s=1$ then the initial term is equal zero.

where,

$P Q_{i}=$ observed probabilities of occurrence of $i$ amount of daily global solar radiation in a given month.

$s=$ the highest observed daily global solar radiation in a given month.

$\xi=$ random numbers between 0 to 1 .

$\mathrm{Q}=$ the stochastically generated global solar radiation for a particular day in a given month.

On the other hand, the monthly maximum value of global solar radiation obtained from the analysis of the actual data were used for the shortwave radiation and evapotranspiration estimation in a clear day of given months.

\section{Derivated solar radiation}

The solar radiation was derivated by daily global solar radiation. The solar radiation is composed of shortwave and longwave radiations. Therefore, both of them were estimated in different climatic and topographical conditions. The shortwave radiation is composed of,

$$
I_{H}=I_{H D}+I_{H S}
$$

where,

$I_{H}=$ total shortwave radiation.

$I_{H D}=$ direct radiation.

$I_{H S}=$ diffused radiation.

The total radiation was estimated by the cosine curve as,

$$
I_{H}=\frac{\pi Q}{2 T_{o}} \cdot \cos \frac{\pi}{T_{o}} \cdot(T-12)
$$

The condition for this relation is, if $I_{H}<0$ then $I_{H}=\mathrm{O}$.

where,

$I_{H}=$ daily total shortwave radiation $\left(\mathrm{kcal} \mathrm{m}^{-2} \mathrm{~h}^{-1}\right)$.

$\mathrm{Q}=$ daily global solar radiation $\left(\mathrm{kcal} \mathrm{m}^{-2}\right)$. 
$T_{o}=$ day length $(\mathrm{h})$.

$T=$ local time.

According to the method of IEA reported by Murai (1978), the relation for computation of extraterrestrial radiation takes the form as,

$$
I_{o}=1164+38 \cdot \sin \frac{360(89+D)}{365}
$$

where,

$I_{o}=$ extraterrestrial radiation $\left(\mathrm{kcal} \mathrm{m}^{-2} \mathrm{~h}^{-1}\right)$.

$D=$ number of the day within a year starting January the 1 st.

The some other relations which are concerned for shortwave radiation estimation are,

$$
\begin{gathered}
I_{O H}=I_{o} \cdot \sin \phi \\
p p=\frac{I_{H}}{I_{O H}} \\
I_{N D}=1540 \cdot p p-470
\end{gathered}
$$

The conditions for above relation are, if $I_{N D}>860$ then $I_{N D}=860$, if $I_{N D}<0$ then $I_{N D}=0$.

Now, the diffused radiation has taken the form of,

$$
I_{H S}=I_{H}-I_{N D} \cdot \sin \phi
$$

The condition for this relation is, if $\mathrm{I}_{H S}<0$ then $\mathrm{I}_{H S}=0$.

The total accepted shortwave radiation in actual topographic condition is derived as,

$$
I_{P}=\cos \psi \cdot I_{N D}+\frac{1+\cos \epsilon}{2} \cdot I_{H S}+\rho \cdot \frac{1-\cos \epsilon}{2} \cdot I_{H}
$$

where,

$I_{P}=$ total accepted shortwave radiation in actual topography $\left(\mathrm{kcal} \mathrm{m}^{-2} \mathrm{~h}^{-1}\right)$.

$\psi=$ angle in between the sun ray and normal vector of field.

$\epsilon=$ slope of the landscape.

$\rho=$ reflective coefficient of land.

The above mentioned relations were adopted to evaluate the distribution of shortwave radiation on typical mean topographic condition of Kikai Island with 20" slope in north as well as south facing fields in a clear day. The results for the case of June and December are presented in Fig. 10 and Fig. 11, respectively. The amount of total incoming shortwave radiations are almost similar in June. But, the results shows a difference in between the amount of incoming total shortwave radiations on north facing and on south facing fields in December. The values of shortwave radiation are higher in June and smaller in December. It is considered due to the different positions of the sun in these months. Because, the sun will be in far south from the equinox in December than in June. This makes the smaller vertical component of incoming shortwave solar radiation on north facing field in December than in June, which resulted a smaller amount of total incoming shortwave radiation in the case of December. 


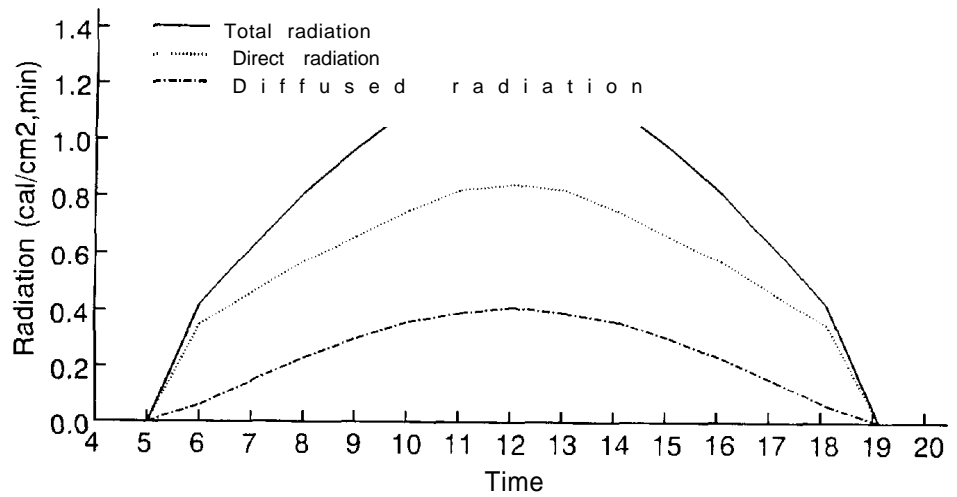

(a) South facing field with $20^{\circ}$ slope

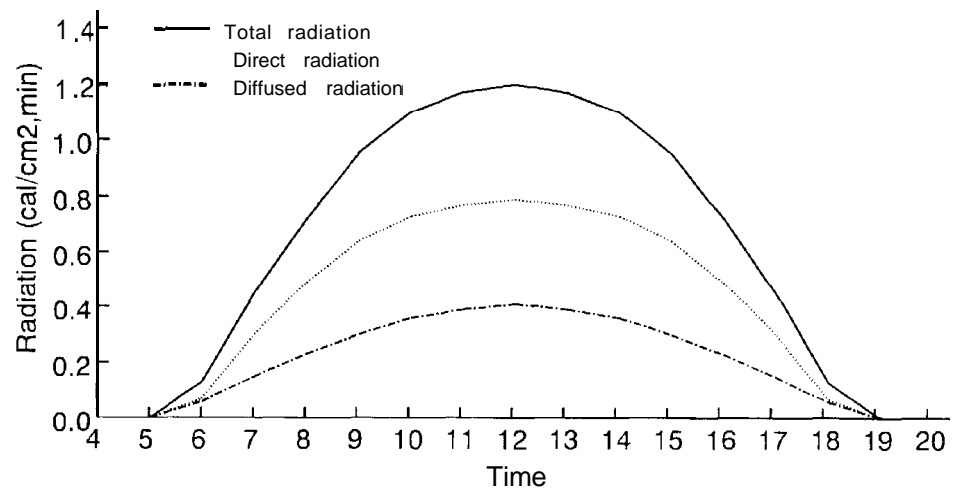

(b) North facing field with $20^{\circ}$ slope

Fig. 10. Distribution of shortwave radiation on 15th June (in clear day).

Furthermore, longwave radiation for clear and cloudy or rainy days have been calculated separately. According to Uchijima (1974), Brunt equation for longwave radiation in the case of clear day takes the form as,

$$
F_{o}=\sigma \cdot T^{4}\left(a_{1}+b_{1} \sqrt{e}\right)
$$

The relation used for longwave radiation in cloudy day is,

$$
F_{n}=F_{o}\left(1-c_{1} \cdot n_{2}\right)
$$

where,

$F_{o}=$ longwave radiation in clear day $\left(\mathrm{cal} \mathrm{cm}^{-2} \mathrm{~min}^{-1}\right)$.

$F_{n}=$ longwave radiation in cloudy day $\left(\mathrm{cal} \mathrm{cm}^{-2} \mathrm{~min}^{-1}\right)$.

$\sigma=$ constant $\left(8.26 \times 10^{-11} \mathrm{cal} \mathrm{cm}^{-2} \mathrm{~min}^{-1} \mathrm{k}^{-4}\right)$.

$T$ =air temperature ("k).

$a_{1}=0.39$ 


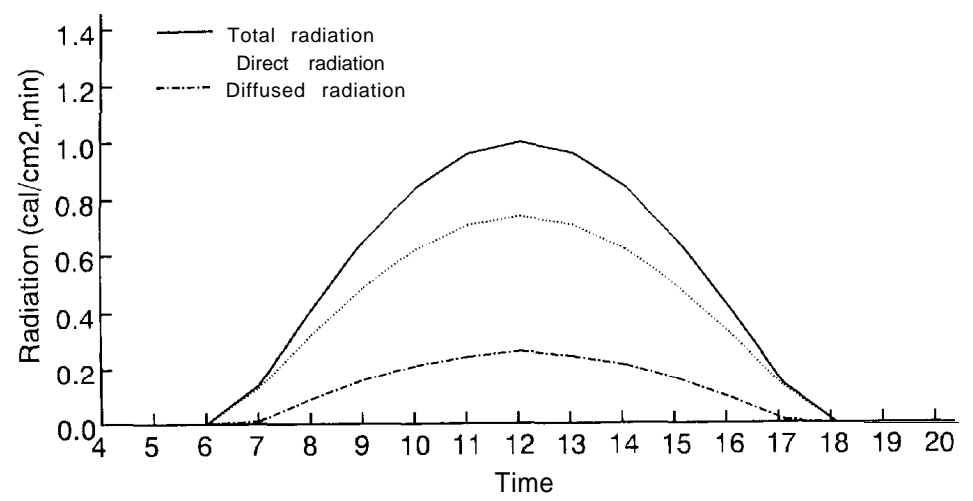

(a) South facing field with 20 ' slope

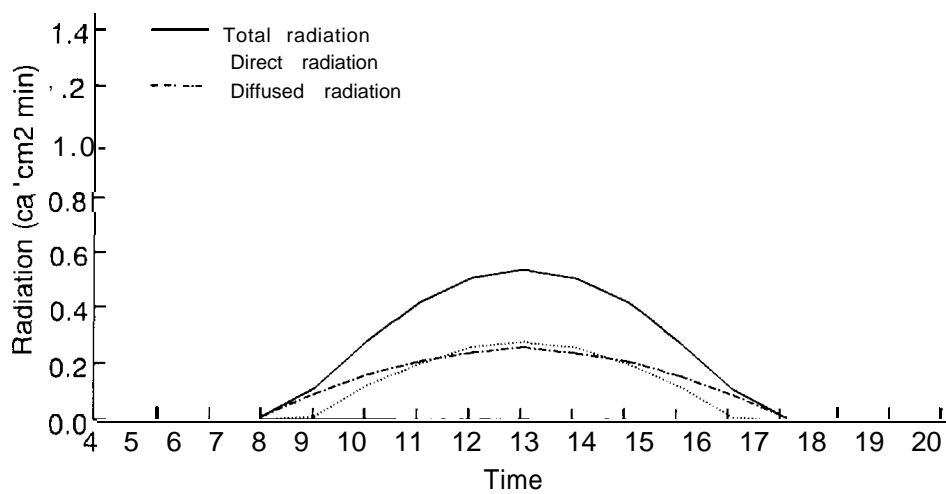

(b) North facing field with $20^{\circ}$ slope

Fig. 11. Distribution of shortwave radiation on 15th December (in clear day).

$$
\begin{aligned}
& b_{1}=0.058 \\
& e=\text { actual vapor pressure }(\mathrm{mmHg}) \\
& c_{1}=0.65 \\
& n=\text { ratio of cloud amount. }
\end{aligned}
$$

\section{Derivated evapotranspiration by solar radiation}

The evaluated total accepted solar radiation by land was used to derive the evapotranspiration on different topographic conditions. The evapotranspiration was estimated by the Penman equation as,

$$
E T_{P}=\frac{\Delta}{\Delta+\gamma} \cdot\left(R_{n}+G\right)+\frac{\gamma}{\Delta+\gamma} 15.36\left(1.0+0.0062 \cdot U_{200}\right)\left(e^{o}-e\right)
$$

where, 


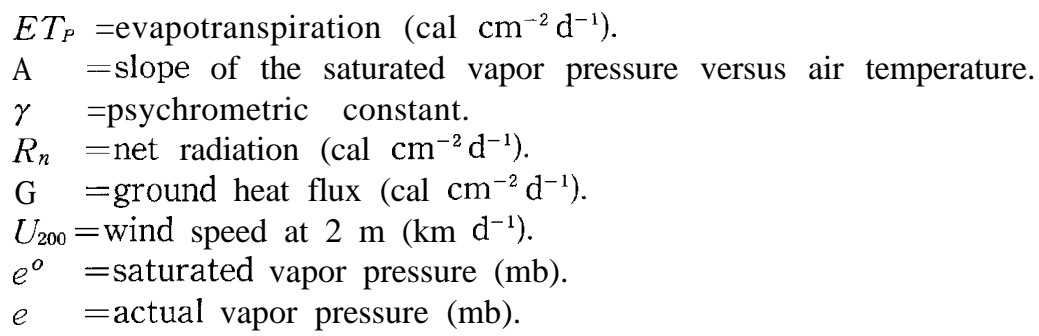

The previously mentioned relations were adopted to determine the total accepted solar radiation on the typical topographic conditions of Kikai Island. Then, the Penman relation was used to determine the evapotranspiration, accordingly. The given typical conditions were flat area and $10^{\circ}, 20^{\circ}, 30^{\prime \prime}$ and $40^{\prime \prime}$ slope on east, west, north and south faces. The Table 1 and Table 2 shows the results of evapotranspiration on the given typical topographic conditions in June and in December in a clear day. The daily evapotranspirations in June are higher on all topographic conditions than that of December. Furthermore, the differences among the distributed evapotranspirations on flat area and on various inclined faces with same degree of slope are not remarkable in June, whereas, the differences among the distributed evapotranspiration are remarkable in December. As already mentioned, evapotranspiration is governed by the amount of total accepted solar radiation by the land. Therefore, the reason for these results is the same reason which has already explained to clarify the differences in distribution of shortwave radiation on various topographic conditions in previous chapter.

The described theoretical approaches were ultimately adopted to determine the distribution of evapotranspiration on actual topographic condition of experimental site of Kikai Island with considering clear day. The results are presented in Fig. 12 (a) and Fig. 12 (b) for the case of June and December, respectively. The evapotranspirations

Table 1. Distribution of evapotranspiration $(\mathrm{cm} / \mathrm{d})$ in clear day of June $15^{\text {th }}$.

\begin{tabular}{ccccc}
\hline Faces & 10' slope & 20”'slope & 30' slope & 40” slope \\
East face & 0.86 & 0.88 & 0.92 & 0.99 \\
West face & 0.86 & 0.88 & 0.92 & 0.99 \\
North face & 0.84 & 0.83 & 0.82 & 0.83 \\
South face & 0.88 & 0.92 & 0.96 & 1.02 \\
\hline Flat area : & 0.86 & & \\
\hline
\end{tabular}

Table 2. Distribution of evapotranspiration $(\mathrm{cm} / \mathrm{d})$ in clear day of December $15^{\text {th }}$.

\begin{tabular}{lcccc} 
Faces & 10 ” slope & $20^{\prime}$ slope & $30^{\circ}$ slope & $40^{\prime}$ slope \\
\hline East face & 0.52 & 0.53 & 0.56 & 0.60 \\
West face & 0.52 & 0.53 & 0.56 & 0.60 \\
North face & 0.45 & 0.40 & 0.35 & 0.33 \\
South face & 0.57 & 0.64 & 0.72 & 0.83 \\
Flat area : & & & & \\
\hline
\end{tabular}




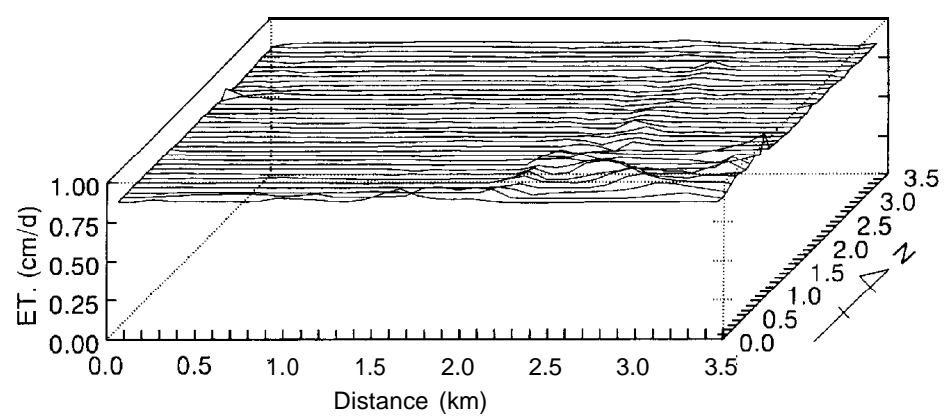

(a) 15th June

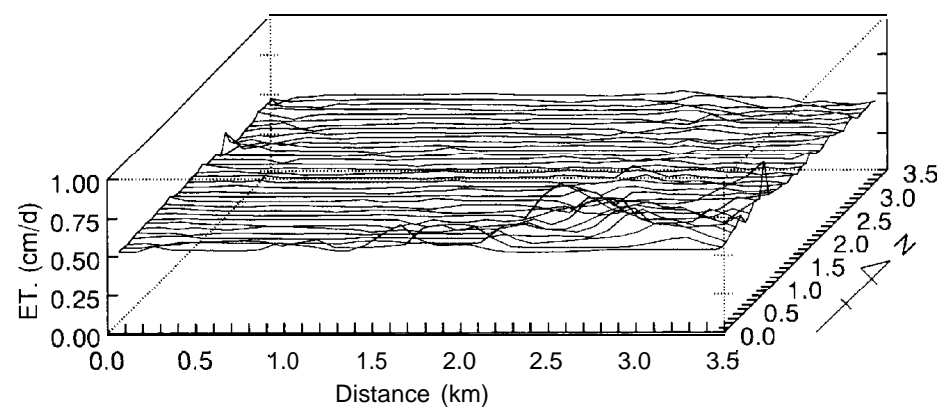

(b) 15th December

Fig. 12. Daily evaportranspiration on each plate of experimental area (in clear day).

among the grid points are higher and more or less similar in June, whereas, they are smaller and not similar in December.

\section{Prediction of daily rainfall}

The monthly probabilities of occurrence of particular intensities of rainfall $\left(k_{i}\right)$ are derived from analyzing the sufficient numbers of past years' rainfall data. The monthly distribution of rainfall is affected by the typhoon, by the development of the meteorological front, etc,. In these cases the amount of rainfall are significantly higher than the amount in the normal rainfall. The procedure of rainfall generation is presented in Fig. 13 (a) and Fig. 13 (b) for June and December, respectively, in the case of Naze Amami Island. The distribution of monthly rainfall were categorized into 3 groups to best fit the regression line obtained from the Least Square analysis for minimizing the errors in the generated rainfalls. The relation for Least Square analysis mentioned by T. Ishihara and S. Ikebuchi (1972) has the form of,

$$
\log _{e} P e_{i}\left(k_{i}\right)=a \cdot k_{i}+b
$$




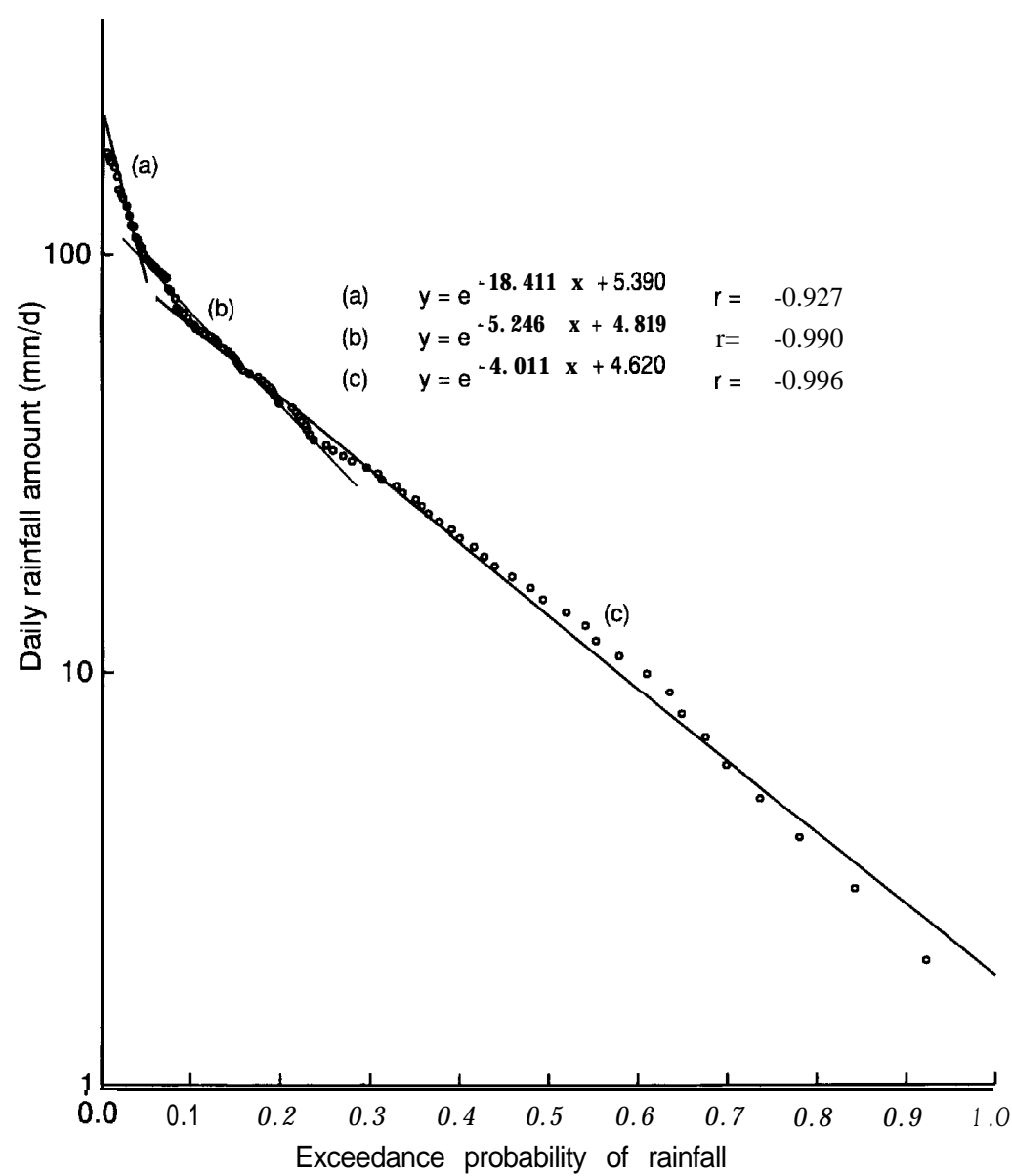

Fig. 13. (a) Regressions of the daily amount of rainfalls on the exceedance probabilities of rainfall in the case of June.

$$
k_{i}=1.0-\sum_{i=1}^{m} P e_{i}
$$

where,

$k_{i}=$ observed monthly probability of exceedance of $i \mathrm{~mm} / \mathrm{d}$ intensity of rainfall.

$P e_{i}=$ observed daily rainfall with $i \mathrm{~mm} / \mathrm{d}$ intensity for a given month.

$m=$ the highest observed daily intensity of rainfall for a given month.

$a \& b=$ constants.

The relations used to find out the optimized constants a and $b$ and correlation coefficient $r$ are as follows,

$$
a=\left(n \cdot \sum_{i=1}^{n} x_{i} \cdot y_{i}-\sum_{i=1}^{n} x_{i} \sum_{i=1}^{n} y_{i}\right) /\left(n \cdot \sum_{i=1}^{n} x_{i}^{2}-\left(\sum_{i=1}^{n} x_{i}\right)^{2}\right)
$$




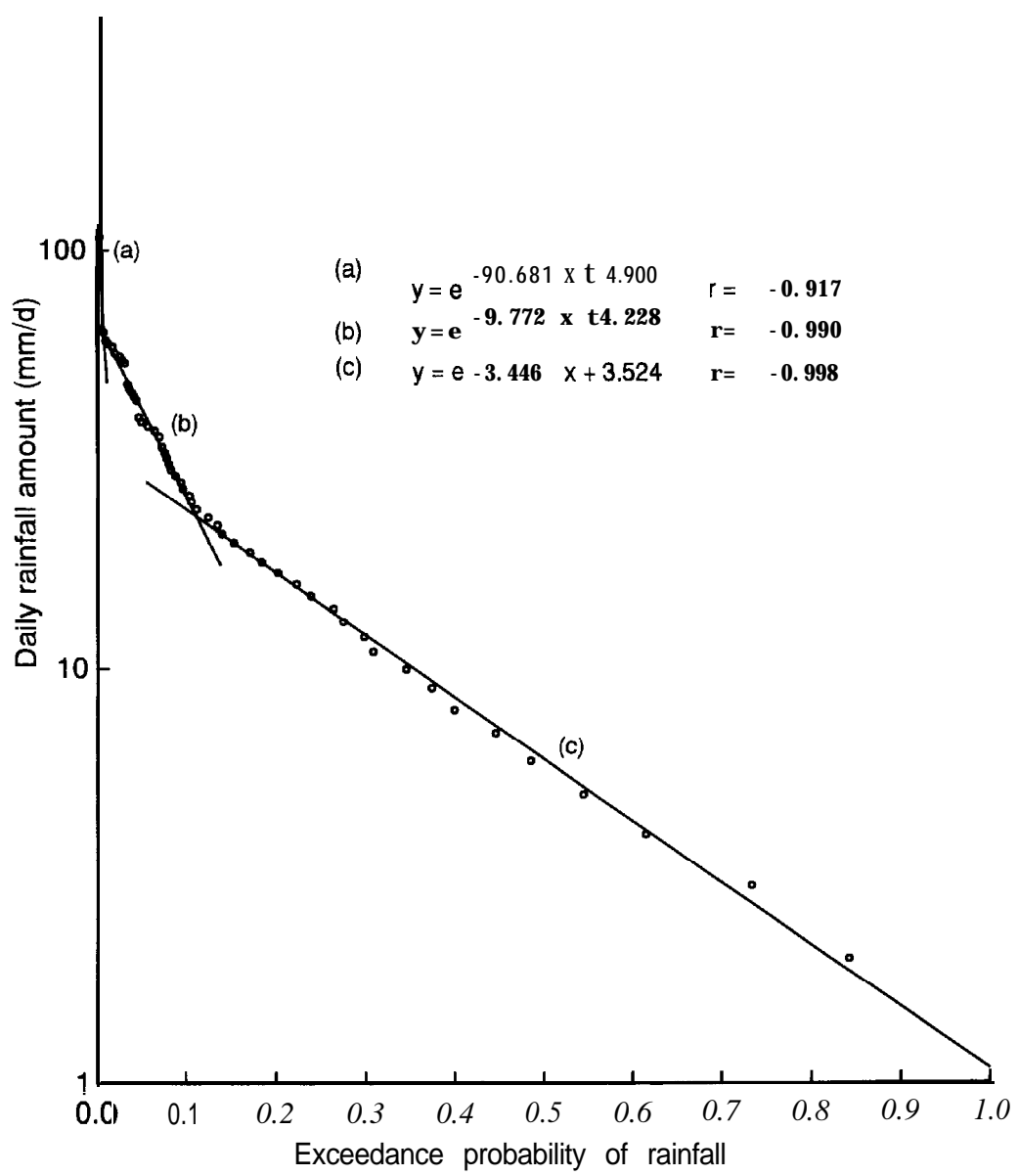

Fig. 13. (b) Regressions of the daily amount of rainfalls on the exceedance probabilities of rainfall in the case of December.

$$
\begin{gathered}
b=\left(\sum_{i=1}^{n} x_{i}^{2} \cdot \sum_{i=1}^{n} y_{i}-\sum_{i=1}^{n} x_{i} \sum_{i=1}^{n} x_{i} \cdot y_{i}\right) /\left(n \cdot \sum_{i=1}^{n} x_{i}^{2}-\left(\sum_{i=1}^{n} x_{i}\right)^{2}\right) \\
r=\left(n \cdot \sum_{i=1}^{n} x_{i} \cdot y_{i}-\sum_{i=1}^{n} x_{i} \sum_{i=1}^{n} y_{i}\right) /\left[\left(n \cdot \sum_{i=1}^{n} x_{i}^{2}-\left(\sum_{i=1}^{n} x_{i}\right)^{2}\right)^{\frac{1}{2}}\right. \\
\left.\cdot\left(n \cdot \sum_{i=1}^{n} y_{i}^{2}-\left(\sum_{i=1}^{n} y_{i}\right)^{2}\right)^{\frac{1}{2}}\right]
\end{gathered}
$$

where,

$n=$ total number of observed rainy days in a given month for 30 years.

$x_{i}=k_{i}$

$y_{i}=\log _{e} P e_{i}\left(k_{i}\right)$

Thus, the rainfall are generated stochastically as, 


$$
P e(\xi)=e^{a \cdot \xi+b}
$$

where,

$$
\begin{aligned}
& P e(\xi)=\text { simulated daily rainfall }\left(\mathrm{mm} \mathrm{d}^{-1}\right) . \\
& \xi \quad=\text { random numbers between } 0 \text { to } 1 .
\end{aligned}
$$

\subsection{Analysis of monthly rainfall}

As above mentioned the monthly rainfall of Naze Amami Island were analyzed with categorizing into 3 groups for predicting very close values to actual rainfall. The categorization of monthly rainfall and values of $a, b$, and $r$ are presented in Table 3 . The results of monthly means and standard deviations of rainfalls are presented in Table 4 for actual and predicted cases.

\subsection{Analysis of annual rainfall}

The results of probabilities of occurrence of particular amount of annual rainfalls, by the Hazen plot method, for Naze Amami Island are shown in Fig. 14 (a) and Fig. 14 (b) for actual and simulation cases, respectively. The simulated amount of annual rainfalls were well resembled with actual amount of annual rainfalls. The rainfalls were generated for 200 times randomly for annual rainfall simulation, whereas, 30 years' annual rainfall data were used in actual case. The actual annual rainfalls were distributed within the range of $1671.4 \mathrm{~mm}-3817.5 \mathrm{~mm}$, whereas, the simulated annual rainfalls were distributed with the range of $1679.3 \mathrm{~mm}-3570.5 \mathrm{~mm}$. The upper limit of simulated amount of annual rainfall was slightly lower than that of actual case. It is due to the very less probabilities of getting the higher amount of rainfall (i. e. more than $400 \mathrm{~mm} / \mathrm{d}$ ), which was occurred by the typhoon, in the actual case.

\section{IRRIGATION SCHEDULING AND DROUGHT OCCURRING SEASON}

\section{Soil water balancing}

The daily available soil moisture was the basis for estimating the annual amount of water application through soil water balancing. Irrigation, rainfall, soil moisture content and evapotranspiration were considered as the affecting parameters in soil water balance and the parameters reduce the soil water balance equation as,

$$
E T_{P}=I+P_{e}-D_{r z}\left(\theta_{i-1}-\theta_{i}\right)
$$

where,

$E T,=$ crop evapotranspiration $\left(\mathrm{mm} \mathrm{d}^{-1}\right)$.

$I \quad=$ Irrigation $\left(\mathrm{mm} \mathrm{d}^{-1}\right)$.

$D_{r z}=$ depth of root zone (mm).

$\theta_{i-1}, \theta_{i}=$ volumetric soil moisture content in $i_{-1}^{\text {th }} \& i^{\text {th }}$ day, respectively, in fraction. $P e=$ rainfall $\left(\mathrm{mm} \mathrm{d}^{-1}\right)$.

\section{Impact of drought occurring season on irrigation scheduling}

The described models were applied to generate daily rainfalls and evapotranspirations on the typical topographic conditions of the experimental site of Kikai Island for water consumption analysis for 10 years in different faces. The results of amount of 
Table 3. Categorization of monthly rainfalls and the values of constants a and $\mathrm{b}$ in equation 58 .

\begin{tabular}{|c|c|c|c|c|}
\hline Months & $\begin{array}{l}\text { Category of rainfall } \\
(\mathrm{mm} / \mathrm{d})\end{array}$ & $\begin{array}{c}\text { a } \\
\text { (in } \log \text { ) }\end{array}$ & $\begin{array}{c}\mathrm{b} \\
\text { (in } \log \text { ) }\end{array}$ & $\begin{array}{c}\mathrm{r} \\
\text { (corr. coef) }\end{array}$ \\
\hline 1 & $\begin{array}{r}1.5-25 \\
26-60 \\
>60\end{array}$ & $\begin{array}{r}-3.49 \\
-8.45 \\
-57.88\end{array}$ & $\begin{array}{l}3.58 \\
4.20 \\
5.11\end{array}$ & $\begin{array}{l}-0.99 \\
-0.99 \\
-0.98\end{array}$ \\
\hline 2 & $\begin{array}{r}1.5-25 \\
26-45 \\
>45\end{array}$ & $\begin{array}{r}-3.20 \\
-8.86 \\
-36.00\end{array}$ & $\begin{array}{l}3.46 \\
3.95 \\
4.57\end{array}$ & $\begin{array}{l}-0.99 \\
-0.98 \\
-0.97\end{array}$ \\
\hline 3 & $\begin{array}{r}1.5-25 \\
26-45 \\
>45\end{array}$ & $\begin{array}{r}-3.16 \\
-4.84 \\
-23.43\end{array}$ & $\begin{array}{l}3.69 \\
3.93 \\
4.57\end{array}$ & $\begin{array}{l}-0.99 \\
-0.98 \\
-0.98\end{array}$ \\
\hline 4 & $\begin{array}{r}1.5-25 \\
26-60 \\
>60\end{array}$ & $\begin{array}{c}-3.54 \\
-5.43 \\
-17.64\end{array}$ & $\begin{array}{l}3.95 \\
4.25 \\
4.75\end{array}$ & $\begin{array}{l}-0.99 \\
-0.99 \\
-0.99\end{array}$ \\
\hline 5 & $\begin{array}{r}1.5-45 \\
46-100 \\
>100\end{array}$ & $\begin{array}{r}-3.77 \\
-7.48 \\
-40.18\end{array}$ & $\begin{array}{l}4.29 \\
4.70 \\
5.24\end{array}$ & $\begin{array}{l}-0.99 \\
-0.98 \\
-0.97\end{array}$ \\
\hline 6 & $\begin{array}{r}1.5-45 \\
46-100 \\
>100\end{array}$ & $\begin{array}{r}-4.01 \\
-5.25 \\
-18.41\end{array}$ & $\begin{array}{l}4.62 \\
4.82 \\
5.39\end{array}$ & $\begin{array}{l}-0.99 \\
-0.99 \\
-0.93\end{array}$ \\
\hline 7 & $\begin{array}{r}1.5-25 \\
26-120 \\
>120\end{array}$ & $\begin{array}{r}-3.77 \\
-8.42 \\
-87.77\end{array}$ & $\begin{array}{l}3.95 \\
4.81 \\
5.82\end{array}$ & $\begin{array}{l}-0.99 \\
-0.99 \\
-0.96\end{array}$ \\
\hline 8 & $\begin{array}{r}1.5-45 \\
46-150 \\
>150\end{array}$ & $\begin{array}{r}-3.77 \\
-12.46 \\
-33.56\end{array}$ & $\begin{array}{l}4.13 \\
5.14 \\
5.82\end{array}$ & $\begin{array}{l}-0.99 \\
-0.99 \\
-0.97\end{array}$ \\
\hline 9 & $\begin{array}{r}1.5-55 \\
56-170 \\
>170\end{array}$ & $\begin{array}{r}-4.11 \\
-14.74 \\
-69.23\end{array}$ & $\begin{array}{l}4.30 \\
5.29 \\
6.19\end{array}$ & $\begin{array}{l}-0.99 \\
-0.96 \\
-0.97\end{array}$ \\
\hline 10 & $\begin{array}{r}1.5-45 \\
46-140 \\
>140\end{array}$ & $\begin{array}{c}-3.90 \\
-9.53 \\
-78.56\end{array}$ & $\begin{array}{l}4.26 \\
4.92 \\
5.55\end{array}$ & $\begin{array}{l}-0.99 \\
-0.99 \\
-0.87\end{array}$ \\
\hline 11 & $\begin{array}{r}1.5-25 \\
26-100 \\
>100\end{array}$ & $\begin{array}{c}-3.57 \\
-7.18 \\
-48.49\end{array}$ & $\begin{array}{l}3.87 \\
4.57 \\
5.20\end{array}$ & $\begin{array}{l}-0.99 \\
-0.99 \\
-0.92\end{array}$ \\
\hline 12 & $\begin{array}{r}1.5-25 \\
26-60 \\
>60\end{array}$ & $\begin{array}{l}-3.44 \\
-9.77 \\
-90.68\end{array}$ & $\begin{array}{l}3.52 \\
4.23 \\
4.89\end{array}$ & $\begin{array}{l}-0.99 \\
-0.99 \\
-0.92\end{array}$ \\
\hline
\end{tabular}

annual water applications in normal and drought years are presented in Fig. 15 (a) and Fig. 15 (b), respectively. As already mentioned 200 different annual patterns of rainfalls were simulated. Those 10 simulated annual patterns of rainfalls which annual amount of rainfall have return period of $1 / 2$ were considered for estimating normal year's annual amount of water applications. On the same way, those 10 
Table 4. Monthly means and standard deviations of rainfall (mm).

\begin{tabular}{ccccc}
\hline Months & Obs. mean & Obs. st. dev & Sim. mean & Sim. st. dev \\
\hline 1 & 12.62 & 18.21 & 11.73 & 16.47 \\
2 & 11.06 & 12.62 & 10.49 & 11.81 \\
3 & 13.76 & 14.56 & 13.47 & 14.21 \\
4 & 16.48 & 19.25 & 16.15 & 19.07 \\
5 & 21.62 & 26.47 & 21.17 & 25.65 \\
6 & 28.39 & 36.61 & 27.72 & 34.79 \\
7 & 19.91 & 34.92 & 19.30 & 30.28 \\
8 & 23.31 & 41.86 & 21.86 & 37.98 \\
9 & 24.95 & 49.41 & 24.35 & 47.31 \\
10 & 21.88 & 30.91 & 22.04 & 30.90 \\
11 & 17.39 & 24.38 & 17.27 & 22.89 \\
12 & 11.65 & 15.17 & 11.44 & 14.26 \\
\hline
\end{tabular}

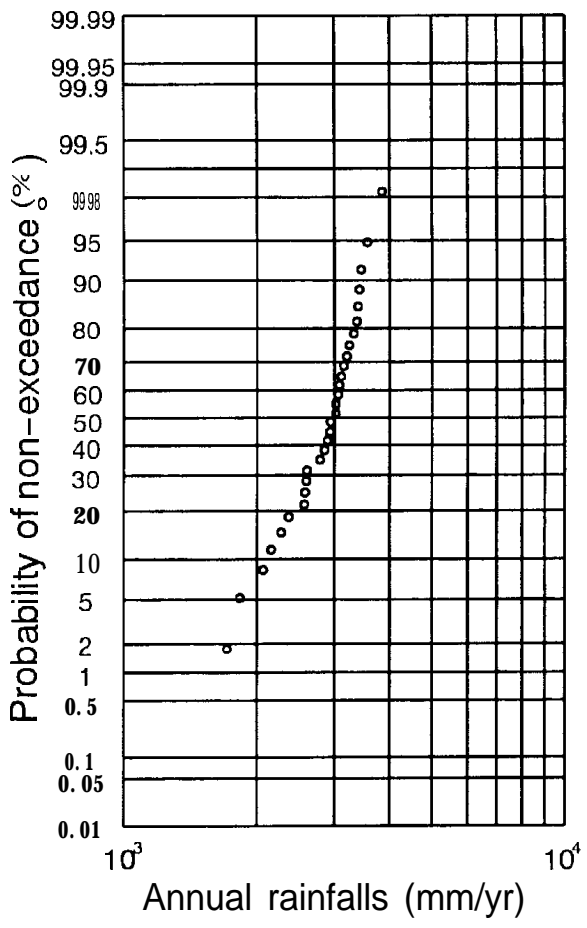

(a) Actual

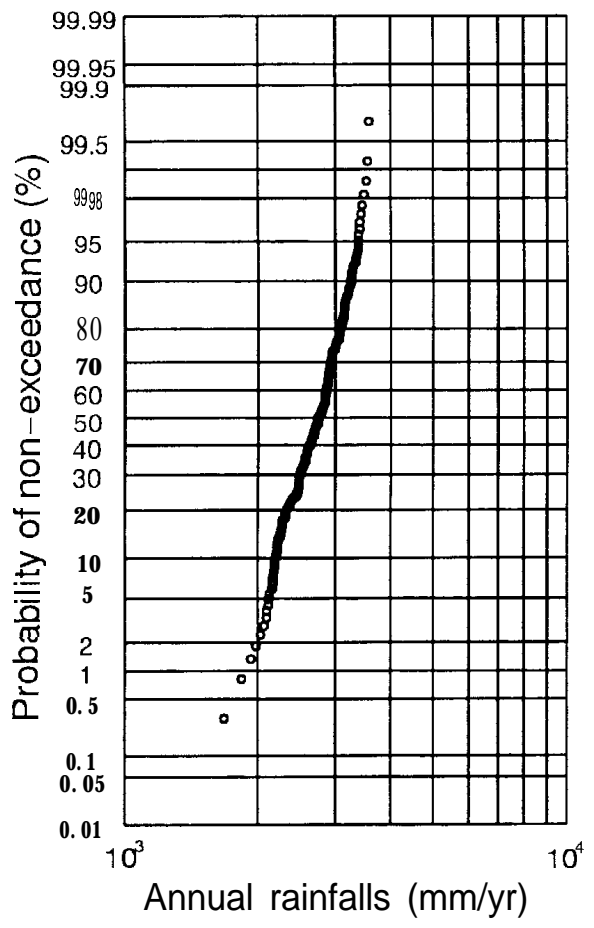

(b) Simulated

Fig. 14. Probabilities of occurrence of annual rainfalls.

annual patterns of rainfalls which annual amount of rainfall have return period of $1 /$ 10 were considered for estimating drought year's annual amount of water applications. The estimated results are shown in Table 5 . 


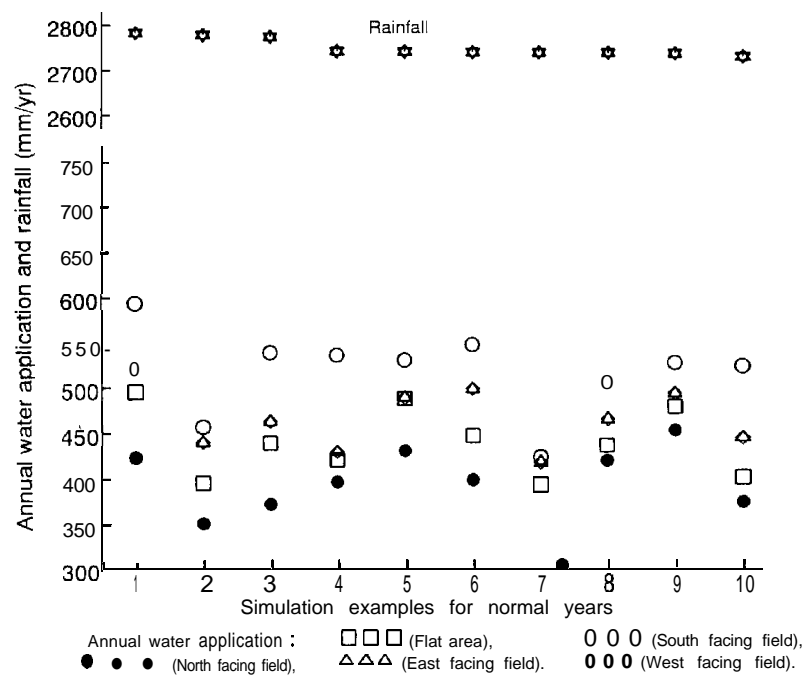

Fig. 15. (a) Annual amount of water applications in normal years on flat area and on various faces with 20 " slope (annual rainfalls with $1 / 2$ return period i. e. about $2800 \mathrm{~mm} / \mathrm{yr}$ are considered for analysis).

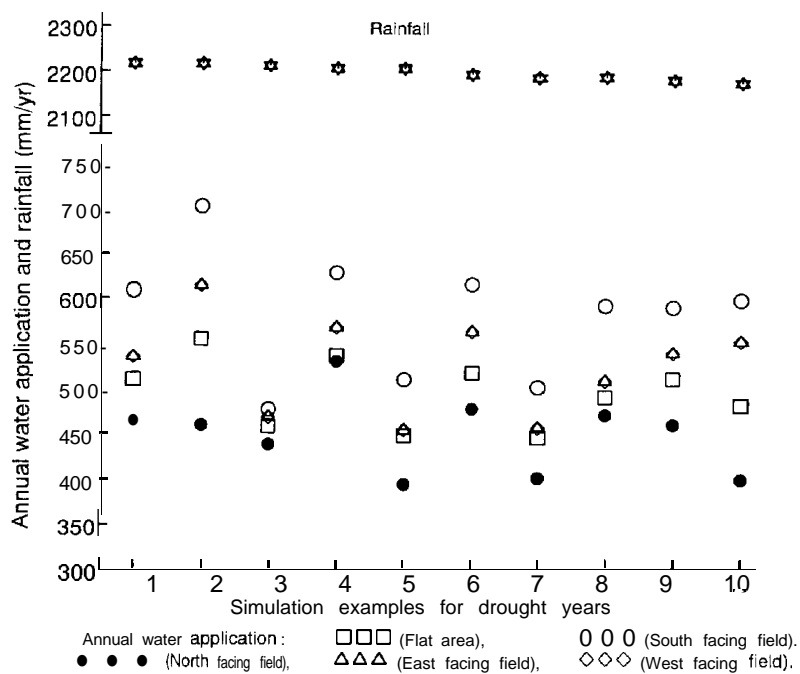

Fig. 15. (b) Annual amount of water applications in drought years on flat area and on various faces with 20 , slope (annual rainfalls with $1 / 10$ return period i. e. about $2200 \mathrm{~mm} / \mathrm{yr}$ are considered for analysis). 
Table 5. Estimated annual amount of water consumption $(\mathrm{mm} / \mathrm{yr})$ on different faces with 20 " slope and on flat area.

\begin{tabular}{ccc}
\hline Faces & Normal Year & Drought Year \\
\hline East face & 467.3 & 524.8 \\
West face & 467.3 & 524.8 \\
North face & 392.8 & 448.8 \\
South face & 519.1 & 581.1 \\
Flat area & 440.3 & 494.4 \\
\hline
\end{tabular}

According to Table 5 the average estimated amount of annual water application in the case of normal year were $467.3 \mathrm{~mm}, 467.3 \mathrm{~mm}, 392.8 \mathrm{~mm}, 519.1 \mathrm{~mm}$ and $440.3 \mathrm{~mm}$ on east facing, west facing, north facing, south facing fields (with 20" slope) and on flat area, respectively. The average estimated amount of annual water application in the case of drought year were $524.8 \mathrm{~mm}, 524.8 \mathrm{~mm}, 448.8 \mathrm{~mm}, 581.1 \mathrm{~mm}$ and $494.4 \mathrm{~mm}$ on east facing, west facing, north facing, south facing fields (with 20" slope) and on flat area, respectively (Table 5). In the both cases the distributed amount of annual water applications are quite different from one year to another in all topographic conditions. It is mainly due to the different drought occurring season in different years. For example, drought occurs sometimes in winter, sometimes in spring, sometimes in summer and sometimes in autumn. It significantly affects in the amount of annual water applications, although, the annual amount of rainfalls are almost similar in all years.

\section{CONCLUSIONS}

The conclusions drawn from this research are briefly highlighted as under mention.

1. In summer, the evapotranspirations are more or less similar on the both flat area and slightly inclined topography as shown in Table 1 . In winter, the evapotranspirations differ with the topographic conditions. South facing field has the highest evapotranspiration and north facing field has the lowest evapotranspiration than other types of field as shown in Table 2 .

2. The intervals of irrigation must be frequent and almost similar on the both flat area and slightly inclined topographic conditions in summer, whereas, in winter the south facing field needs the frequent irrigation applications and north facing field needs the less frequent applications than other types of field.

3. The higher amount of annual irrigation water must be managed for the south facing field and the lower for the north facing field than for other types of field as shown in Table 5 .

4. The annual amount of water application is affected by the drought occurring season, although, the annual amount of rainfalls are same for each years as shown in Fig. 15.

5. The capacities of irrigation systems should be designed with considering the topographic conditions to meet the crop water requirement. 


\section{REFERENCES}

Ishihara, T. and S. Ikebuchi 1972 A study on the stochastic structures of daily precipitation and their simulation. Proc. JSCE 197 : 57-69 (in Japanese)

Jones, J. W., R. F. Colwick and E. D. Threadgill 1972 A simulated environmental model of temperature, evaporation, rainfall and soil moisture. Trans. ASAE, 15 (2) : 366-372

Kuroda, M. and Y. Nakano 1992 Irrigation scheduling and water application. In "Update Topics of Upland Irrigation", Hatachinogyo Sinkokai, Tokyo, pp. 184-214 (in Japanese)

Murai, K. 1978 Amount and intensity of solar radiation. In "Basic Theory and Application of Solar Energy", ed. by Soc. of Japan solar energy, Omusha, Tokyo, pp. 1-34 (in Japanese)

Tajima, T., H. Ono, Y. Sakata and M. Sugiura 1977 Computer graphics. Korona Pub., Tokyo, pp. 27-45 (in Japanese)

Tani, N. 1974 Investigation on shading of solar radiation. In "Handbook of Agriculture Meteorology", ed. by Tsuboi, Yokendo Pub., Tokyo, pp. 793-797 (in Japanese)

Uchijima, Z. 1974 Radiation condition on farm. In "Handbook of Agriculture Meteorology", ed. by Tsuboi, Yokendo Pub., Tokyo, pp. 70-92 (in Japanese) 